\title{
Engaging NHS staff in research
}

\author{
Wider participation is vital to improve patient care
}

\author{
Jill Maben professor of health services research and nursing ${ }^{1}$, Angela King patient advocate and \\ carer $^{2}$
}

${ }^{1}$ School of Health Sciences, University of Surrey, Guildford, Surrey, UK; ${ }^{2}$ London, UK

Calls by the Royal College of Physicians (RCP) for more research in NHS trusts and the Care Quality Commission's (CQC) decision to award extra points to trusts doing research, seem to signal a new era for research in the NHS.

The RCP statement Delivering Research for All ${ }^{1}$ says every NHS clinician should be supported to take part in research. Highlighting evidence that research active trusts have better patient outcomes, the college calls for protected time for doctors, nurses, and other clinicians to undertake research. In collaboration with the National Institute for Health Research, the CQC will add questions to the leadership inspection framework for providers (the well led framework) that recognise the role of research in high quality patient care and strengthen the assessment of research activity. ${ }^{23}$

An increase in research capacity is welcome, but there are serious challenges to implementation. Substantial change, some might say a revolution, will be required in the way research is conducted in the NHS.

A report by RAND Europe ${ }^{4}$ commissioned by the Healthcare Improvement Studies (THIS) Institute, recently identified the barriers to expanding research activity within the NHS. They include failure to recognise research contributions in job plans, appraisals systems, and career pathways; lack of individual capacity, research knowledge, and skills; poor access to relevant training; no dedicated time for research; and a perception that research is a specialist activity outside the domains of some healthcare professions.

Currently, there is no real expectation for nurses and midwives to lead research, ${ }^{5}$ yet as the largest workforce, they are a valuable and underused resource. A lack of knowledge and skills remains an important barrier for these staff groups, who have fewer opportunities and less access to ongoing research training than doctors, particularly early in their careers. ${ }^{6}$ The RAND Europe report includes interviews with experts on healthcare professionals' engagement with research but notably excludes conversations with research active nurses, midwives, and allied health professionals to inform future research opportunities for these staff.
Perhaps not surprisingly, the report highlights a neglect of NHS staff involvement in research compared with patient and public involvement (PPI). ${ }^{4}$ PPI in research has attracted major policy support, and ongoing studies and evaluations provide us with useful learning. Those who have contributed to this learning could share their valuable work and experience with NHS staff groups to avoid "research wastage" ${ }^{\text {"7 }}$ and foster a better understanding of shared values and priorities for research. The priority setting methods used by the James Lind Alliance, ${ }^{48}$ for example, show the value of collaboration, and these could be developed further, providing a way forward for setting research priorities that includes a wide range of NHS staff.

Evidence of the effects of engaging NHS staff in research is scarce. Boaz and colleagues conducted a three stage review of studies on research engagement in $2015^{9}$ and found that most (28 out of 33) suggested an improvement in healthcare performance was associated with greater staff engagement in research. However, only seven of these 28 studies reported improved health outcomes; the rest reported only improved (usually more evidence based) processes of care. The authors conclude that involvement in research helps improve healthcare performance through several mechanisms, so multiple parallel strategies to enhance engagement are required.

\section{Fresh approach}

The RCP and CQC announcements are a start, but will not by themselves remove barriers to widespread staff involvement in research. Real and sustained progress will require a fresh approach, and citizen science ${ }^{10}$ could provide the new tools necessary. ${ }^{11}$ Crowdsourcing, for example, draws on a large pool of people to gather ideas, funding, or labour. It can be used in research projects where citizens (clinicians, patients, and the public) help collect and analyse data, allowing research at much greater scale and increasing efficiency in terms of speed, throughput, and cost.

One recent example, Cell Slider, had 100000 citizen scientists analysing 180000 breast tissue samples for oestrogen receptor data. ${ }^{12}$ Benefits for contributors include increased understanding of research processes and opportunities for both informal 
learning and more formal professional development. These methods also draw on a greater diversity of perspectives and can involve non-researchers, including a wider range of NHS staff, patients, and the public.

The RAND Europe report suggests that systems must change fundamentally to allow more training opportunities for NHS staff and make engagement in research an important part of career progression for all staff, not only doctors. The passion and energy that fuel the best research can be harnessed to bring about greater inclusion and ultimately a more reliable evidence base for healthcare. This is a perfect opportunity for all royal colleges and academies to produce a collective statement detailing what they will do to help make research in the NHS the best it can be.

Competing interests: We have read and understood BMJ policy on declaration of interests and declare the following interests: JM receives research funding from the National Institute for Health Research, UK, and both authors are members of the engagement and involvement advisory board of THIS Institute, University of Cambridge. AK is a lay reviewer for several NIHR programmes and a member of the Health Foundation's College of Assessors.

Provenance and peer review: Commissioned; not externally peer reviewed.

1 Royal College of Physicians. Delivering research for all: expectations and aspirations for the NHS in England. 2019. https://www.rcplondon.ac.uk/guidelines-policy/deliveringresearch-all-expectations-and-aspirations-nhs-england
2 Care Quality Commission. Trust-wide Well-Led Inspection FrameworkV6. 2018. https:// www.cqc.org.uk/sites/default/files/20190412_Trust_wide_well_led_inspection_framework v6.pdf

3 NIHR. CQC Inspections to give more exposure to clinical research taking place in the NHS. 2018. https://www.nihr.ac.uk/news/cqc-inspections-to-give-more-exposure-to-clinicalresearch-taking-place-in-nhs-trusts/11185

4 Dimova S, Prideaux R, Ball S, Harshfield A, Carpenter A, Marjanovic S. Enabling NHS Staff to contribute to Research: reflecting on current practice and informing future opportunities. RAND Europe, 2018. https://www.rand.org/pubs/research_reports/RR2679. $\mathrm{html}$

5 Moore J, Crozier K, Kite K. An action research approach for developing research and innovation in nursing and midwifery practice: building research capacity in one NHS foundation trust. Nurse Educ Today 2012;32:39-45. 10.1016/..nedt.2011.01.01421333419

6 Roberts R, Perry N, Phillips A, Richardson D, Soni S. Clinical research should be a priority in the NHS-but what do genito-urinary medicine clinic staff think? Int J STD AIDS 2015;26:107-12. 10.1177/0956462414531241 24713229

7 Welsman J, Gibson A, Heaton J, Britten N. Involving patients and the public in healthcare operational research. BMJ 2014;349:g4903. 10.1136/bmj.g4903 25078554

8 Boney $\mathrm{O}$, Bell M, Bell N, etal . Identifying research priorities in anaesthesia and perioperative care: final report of the joint National Institute of Academic
Anaesthesia/James Lind Alliance Research Priority Setting Partnership. BMJ Open 2015;5:e010006. 10.1136/bmjopen-2015-010006. 26674506

9 Boaz A, Hanney S, Jones T, Soper B. Does the engagement of clinicians and organisations in research improve healthcare performance: a three-stage review. BMJ Open 2015;5:e009415. 10.1136/bmjopen-2015-009415 26656023

10 Simmonds R. Using citizen science to boost healthcare improvement research. BM Opinion, 30 Jun 2018. https://blogs.bmj.com/bmj/2018/11/30/rebecca-simmons-usingcitizen-science-to-boost-healthcare-improvement-research/

11 Lichten, C, loppolo R, D’Angelo C, Simmonds RK, Morgan Jones M. Citizen science: crowdsourcing for research. THIS Institute, Rand Europe, 2018.

12 Candido Dos Reis FJ, Lynn S, Ali HR, etal . Crowdsourcing the General Public for Large Scale Molecular Pathology Studies in Cancer. EBioMedicine 2015;2:681-9. 10.1016/j.ebiom.2015.05.009 26288840

Published by the BMJ Publishing Group Limited. For permission to use (where not already granted under a licence) please go to http://group.bmj.com/group/rights-licensing/ permissions 